\title{
Hydroxyl Radical Damaged Thymidine-5'-Monophophate Presents Unique Epitopes for Cancer Antibodies
}

\author{
Rizwan Ahmad, Zafar Rasheed* and Rashid Ali
}

Department of Biochemistry, Faculty of Medicine, J.N. Medical College, A.M.U. Aligarh-202002, India

\begin{abstract}
Reactive oxygen species (ROS) plays an important role in carcinogenesis and hydroxyl radical ( $\mathrm{OH})$ contributes to the structural changes in DNA that characterize the cancer like phenotype. The role of hydroxyl radical ( $\mathrm{OH}) \mathrm{dam}-$ aged thymidine 5'-monophosphate (TMP) in cancer patients has been investigated in the present study. TMP was conjugated to bovine serum albumin (BSA), and then TMP-BSA conjugate was modified by hydroxyl radicals. Cancer patients $(n=99)$ were screened by direct binding ELISA for the detection of antibodies against native and ROS-modified conjugates and the results were compared with healthy age-matched controls $(n=29)$. High degree of specific binding by cancer serum antibodies towards ROS modified TMP-BSA conjugate, in comparison to unmodified conjugate $(p<0.05)$ was observed. Healthy individuals showed negligible binding with either antigen. Competitive inhibition ELISA reiterates the direct binding results. Protein-A affinity purified IgG from cancer patients further substantiated the enhanced recognition towards modified conjugate as compared to unmodified conjugate. The present study clearly shows the perturbation in TMP-BSA conjugate by hydroxyl radical presenting unique neo-epitopes on TMP that might from one of the factors in antigen driven induction of antibodies in cancer patients.
\end{abstract}

\section{INTRODUCTION}

Cellular metabolism and ionizing radiation lead to the production of highly reactive oxygen species (ROS) in cells, like the superoxide anion radical, the hydroxyl radical and peoxynitrite etc. These species and their secondary intermediates react with cellular macromolecules and induce in them a variety of chemical alterations leading to carcinogenesis [1-3]. ROS may be looked as a causative agent at all stages of cancer namely initiation, promotion and progression [4]. Damage to DNA by ROS has been widely accepted as a major cause of cancer [5]. Human studies support the experimentally based notion of oxidative DNA damage as an important mutagenic and apparently carcinogenic factor [6]. DNA is considered to be most important target of oxygen free radical (OFR) attack [7]. Oxidative insult to DNA includes a range of specifically oxidized purine and pyrimidine bases as well as alkali labile sites and strand breaks [8,9]. If it relates to critical genes such as oncogenes or tumor suppressor genes, initiation/progression can result [10]. Immunological studies suspect a positive role for ROS-modified DNA in the etiology of cancer $[11,12]$.

In our earlier study, we have shown that thymidine monophosphate (TMP) linked bovine serum albumin (TMPBSA) conjugate and its oxidized form was found to be immunogenic in experimental animals. Induced antibodies against TMP-BSA and ROS-modified TMP-BSA (ROSTMP-BSA) conjugates exhibited appreciable cross-reactivity with various polynucleotides and nucleic acids [13]. In the

*Address Correspondence to this author at the Department of Pathology, Microbiology \& Immunology, School of Medicine, University of South Carolina, 6439 Garners Ferry Road, Columbia, SC 29209, USA. Tel: +1216-650-9487; Fax: +1803-733-5828;

E-mail: Zafar.Rasheed@uscmed.sc.edu present study, we have shown the cross reactivity of experimentally induced anti-TMP-BSA antibodies and anti-ROSTMP-BSA antibodies against native and ROS-modified TMP-BSA conjugates with TMP alone, BSA alone and their ROS-modified conformers. The induced antibodies showed significant inhibition with TMP and ROS-TMP, respectively but with BSA and ROS-modified BSA these antibodies showed negligible inhibition. This suggested that anti-TMPBSA antibodies and anti-ROS-TMP-BSA antibodies were mainly generated against TMP and ROS-TMP, respectively and BSA acts only as a carrier protein. In view of these, the present study was hypothesized that oxidative by-product, like hydroxyl radical $(\cdot \mathrm{OH})$ damaged TMP of DNA, help to initiate autoimmunity in cancer patients. We studied, the presence of circulating autoantibodies in various cancer patients sera directed against neo-epitopes which was generated by hydroxyl radicals on TMP of TMP-BSA.

\section{MATERIALS AND METHODOLOGY}

\section{Collection of Sera}

Sera (non-fasting) were collected from cancer patients with proven histo-pathological diagnosis from J.N. Medical College Hospital, A.M.U. Aligarh and from All India Institute of Medical Sciences, New Delhi. All cancer patients having disease for more than eighteen months and they continuing attending their Out Patient Departments (OPD), severity of cancer vary from patient to patients. The informed consent was obtained from each patient or from patients family members. Sera from normal, healthy individuals served as negative controls. All sera were decomplemented at $56^{\circ} \mathrm{C}$ for 30 minutes and stored in aliquots at $-80^{\circ} \mathrm{C}$.

\section{Modification of Thymidine 5'-Monophosphate}

TMP was modified in PBS $(10 \mathrm{mM}$ sodium phosphate buffer containing $150 \mathrm{mM} \mathrm{NaCl}, \mathrm{pH} \mathrm{7.4)}$ by our published 
procedure [13-16]. An aqueous solution of TMP $(0.31 \mathrm{mM})$ was modified by hydroxyl radical, generated by the irradiation $(30 \mathrm{~min})$ of hydrogen peroxide $(3.1 \mathrm{mM})$ at $254 \mathrm{~nm}$. Excess hydrogen peroxide was removed by extensive dialysis against PBS, $\mathrm{pH}$ 7.4.

\section{Preparation of Antigen}

The TMP was covalently linked to BSA by the carbodiimide method [14]. Aqueous solutions of BSA $(19 \mathrm{mg})$ and TMP $(50 \mathrm{mg}$ ) were mixed and $\mathrm{pH}$ adjusted to 7.5 using $\mathrm{NaOH}$, followed by the addition of $20 \mathrm{mg}$ of carbodiimide, in a total volume of $5 \mathrm{ml}$. The reaction mixture was incubated in darkness at room temperature for $24 \mathrm{~h}$. After incubation, the sample was dialyzed extensively against PBS (pH 7.4).

\section{ROS-Modification of TMP-BSA Conjugate}

TMP-BSA conjugate was modified in PBS (10 mM sodium phosphate buffer containing $150 \mathrm{mM} \mathrm{NaCl}, \mathrm{pH}$ 7.4) by our published procedure $[13,16]$. An aqueous solution of TMP-BSA $(6.2 \mathrm{mM})$ was modified by hydroxyl radical, generated by the UV-irradiation ( $30 \mathrm{~min}$ ) of hydrogen peroxide $(62 \mathrm{mM})$ at $254 \mathrm{~nm}$. Excess hydrogen peroxide was removed by extensive dialysis against PBS, pH 7.4.

\section{Purification of IgG}

Immunoglobulin $\mathrm{G}(\mathrm{IgG})$ was isolated from cancer sera and healthy human sera using Protein A-Sepharose CL-4B column (Sigma Chemicals, St. Louis, MO) $[17,18]$. The homogeneity of the isolated $\operatorname{IgG}$ was checked by performing $7.5 \%$ polyacrylamide gel electrophoresis.

\section{Enzyme Linked Immunosorbent Assay}

An ELISA was carried out on maxisorp immunoplates (NUNC, Roskilde, Denmark) as previously described [18]. Maxisorp microtitre immunoplates were coated with $100 \mu \mathrm{L}$ modified or unmodified TMP-BSA conjugate $(10 \mu \mathrm{g} / \mathrm{mL})$ as antigens in carbonate bicarbonate buffer $(0.05 \mathrm{~mol} / \mathrm{L}, \mathrm{pH}$ 9.6). The plates were coated for $2 \mathrm{~h}$ at $37^{\circ} \mathrm{C}$ and overnight at $4^{\circ} \mathrm{C}$. Each sample was coated in triplicate and half of the plates served as controls without antigen coating. Unbound antigen was washed ( $3 \mathrm{x})$ with TBS-T $(20 \mathrm{mmol} / \mathrm{L}$ Tris, 150 $\mathrm{mmol} / \mathrm{L} \mathrm{NaCl}[\mathrm{pH} 7.4]$ containing $0.05 \%$ Tween-20) and unoccupied sites were blocked with $2 \%$ fat-free milk in TBS $(10 \mathrm{mmol} / \mathrm{L}$ Tris, $150 \mathrm{mmol} / \mathrm{L} \mathrm{NaCl}[\mathrm{pH} 7.4])$ for $4-6 \mathrm{~h}$ at $37^{\circ} \mathrm{C}$. After incubation the plates were washed $(4 \mathrm{x})$ with TBS-T. The test serum serially diluted in TBS-T (100 $\mu 1 /$ well) or Protein-A purified cancer patients $\operatorname{IgG}$ in TBS $\left(100 \mu \mathrm{l} /\right.$ well) was adsorbed for $2 \mathrm{~h}$ at $37^{\circ} \mathrm{C}$ and overnight at $4^{\circ} \mathrm{C}$. Bound antibodies were assayed with anti-human alkaline phosphatase conjugate (Sigma Chemical, St. Louis, MO) using p-nitrophenyl phosphate as substrate (Sigma). The absorbance (A) of each well was monitored at $410 \mathrm{~nm}$ on an automatic microplate reader. Each sample was run in triplicate. The control wells were treated similarly. The results were expressed as mean of difference of absorbance values in test and control wells.

\section{Competitive Inhibition ELISA}

Antigenic specificity of the antibodies was determined by competition ELISA [15-18]. Varying amounts of inhibitors $(0-20 \mu \mathrm{g} / \mathrm{mL})$ were mixed with a constant amount of test serum (1:100 diluted) or affinity purified IgG. The mixture was incubated at room temperature for $2 \mathrm{~h}$ and overnight at $4^{\circ} \mathrm{C}$. The immune complex formed was coated in the wells instead of IgG. The remaining steps were as for the direct binding ELISA. Inhibitors used were unmodified or modified TMP-BSA conjugate. Percentage inhibition was calculated using the formula: Percent inhibition was calculated using the formula:

$$
\text { Percent inhibition }=\left[1-\left(\mathrm{A}_{\text {inhibited }} / \mathrm{A}_{\text {uninhibited }}\right)\right] \times 100
$$

\section{Statistical Analysis}

Data are presented as mean \pm SD. Significance of differences from control values were determined with the Student's $t$ test (Statgraphics, Origin 6.1). A value of $p<0.05$ was considered to indicate statistical significance.

\section{RESULTS}

\section{Characterization of ROS-Modified TMP}

The UV absorption spectra of hydroxyl radical modified TMP indicated a complete loss of characteristic absorption at $260\left(\lambda_{\max }\right)$ after $30 \mathrm{~min}$ of irradiation (Fig. 1). A generalized spectrum getting stronger towards shorter wavelength was observed. No appreciable change in TMP absorption spectra was noticed when irradiated for $30 \mathrm{~min}$ in the absence of hydrogen peroxide.

\section{Conjugation of TMP to BSA}

The UV absorption of TMP-BSA conjugate showed a slight bathochromic shift when compared with TMP alone. The formation of TMP-BSA conjugate was ascertained on $7.5 \%$ non-reducing PAGE. The banding pattern indicated the formation of high molecular weight species as a consequence of conjugation. UV analysis of TMP-BSA conjugate gave a sharp peak at $\lambda_{\max }(269 \mathrm{~nm})$, whereas ROS-modified conjugate indicated substantial hypochromicity and almost a complete disappearance of UV absorption maximum [13].

\section{Cross Reactions of Anti-TMP-BSA Antibodies and Anti- ROS-TMP-BSA Antibodies}

Immunization of TMP-BSA conjugate and ROSmodified TMP-BSA conjugates in rabbits induced high titre antibodies. Fifty percent inhibition of antibody binding was observed at an inhibitor concentration $\left(\mathrm{IC}_{50}\right)$ of $2.5 \mu \mathrm{g} / \mathrm{ml}$ and $3.5 \mu \mathrm{g} / \mathrm{ml}$ with TMP-BSA conjugate and ROS-TMPBSA conjugate, respectively [13]. Here, we have shown the cross-reaction of experimentally induced anti-TMP-BSA antibodies and anti-ROS-TMP-BSA antibodies by competitive inhibition assay using TMP alone, BSA alone and their ROS-modified conformers as inhibitors. Competition ELISA with anti-TMP-BSA conjugate IgG showed the induced antibodies recognized TMP alone as it showed a maximum inhibition of $69 \%$. ROS-TMP alone, BSA alone and ROSBSA alone showed $28 \%, 10 \%$ and $11 \%$ inhibition, respectively. Table 1 (a) summaries the data of the binding characteristics of anti-TMP-BSA conjugate IgG. Competition ELISA with anti-ROS-TMP-BSA conjugate IgG showed a maximum inhibition of $86 \%$ with the ROS-TMP as inhibitor. TMP alone, BSA alone and ROS-BSA alone showed 39\%, $11 \%$ and $13 \%$ inhibition, respectively. Table 1 (b) summa- 


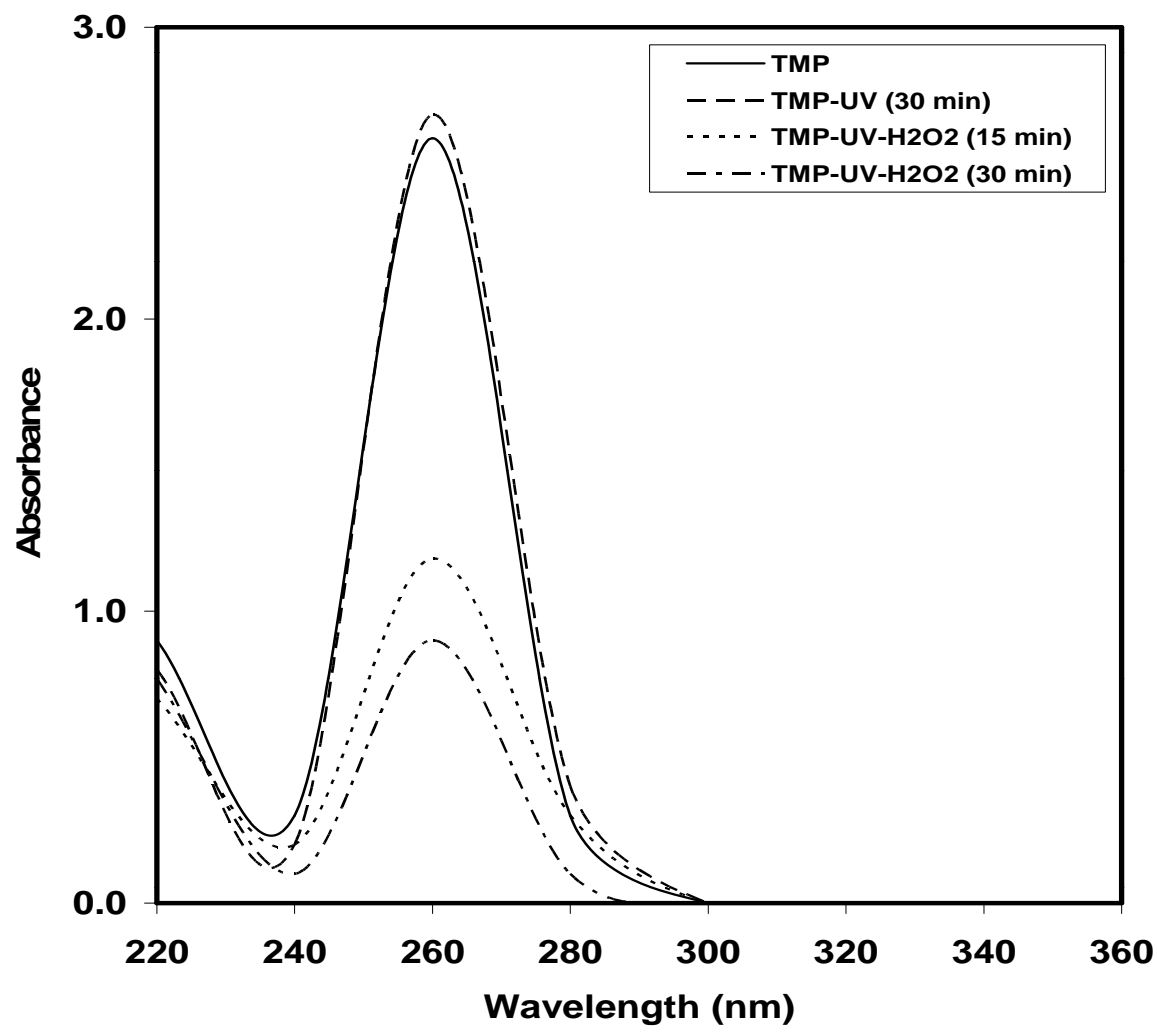

Fig. (1). UV absorption spectra of TMP and hydroxyl radical modified TMP. Hydroxyl radicals were generated by UV irradiation of hydrogen peroxide. All samples were extensively dialyzed against PBS before recording the spectra.

Table 1.

(a) Competitive Inhibition Data of anti-TMP-BSA IgG with Different Inhibitors

\begin{tabular}{|c|c|}
\hline Inhibitor & Max. Percent Inhibition at 20 $\boldsymbol{\mu g} / \mathbf{m l}$ \\
\hline \hline TMP alone & $69 \pm 4.7$ \\
\hline ROS-TMP alone & $28 \pm 5.2$ \\
\hline BSA alone & $10 \pm 2.6$ \\
\hline ROS-BSA alone & $11 \pm 2.1$ \\
\hline
\end{tabular}

(b) Competitive Inhibition Data of anti-ROS-TMP-BSA IgG with Different Inhibitors

\begin{tabular}{|c|c|}
\hline Inhibitor & Max. Percent Inhibition at 20 $\boldsymbol{\mu g} / \mathbf{m l}$ \\
\hline \hline TMP alone & $39 \pm 1.1$ \\
\hline ROS-TMP alone & $86 \pm 6.2$ \\
\hline BSA alone & $11 \pm 1.2$ \\
\hline ROS-BSA alone & $13 \pm 2.2$ \\
\hline
\end{tabular}

Each value represents mean \pm S.D. of eleven independent assays.

ries the data of the binding characteristics of anti-ROS-TMPBSA conjugate IgG.

\section{Detection of Anti-ROS-TMP-BSA Antibodies in Cancer Sera}

The study comprised of ninety nine sera from patients suffering from cancer of different organ and organ systems.
Binding of circulating antibodies in cancer sera (at 1:100 dilution) with TMP-BSA and ROS-modified TMP-BSA conjugate was assessed by direct binding ELISA (Fig. 2a). The average absorbance at $410 \mathrm{~nm}( \pm \mathrm{SD})$ of 99 different cancer sera binding to TMP-BSA and ROS-damaged TMP-BSA conjugate was $0.43 \pm 0.12$ and $0.79 \pm 0.14$, respectively. Whereas, the absorbance at $410 \mathrm{~nm}( \pm \mathrm{SD})$ of 29 healthy hu- 

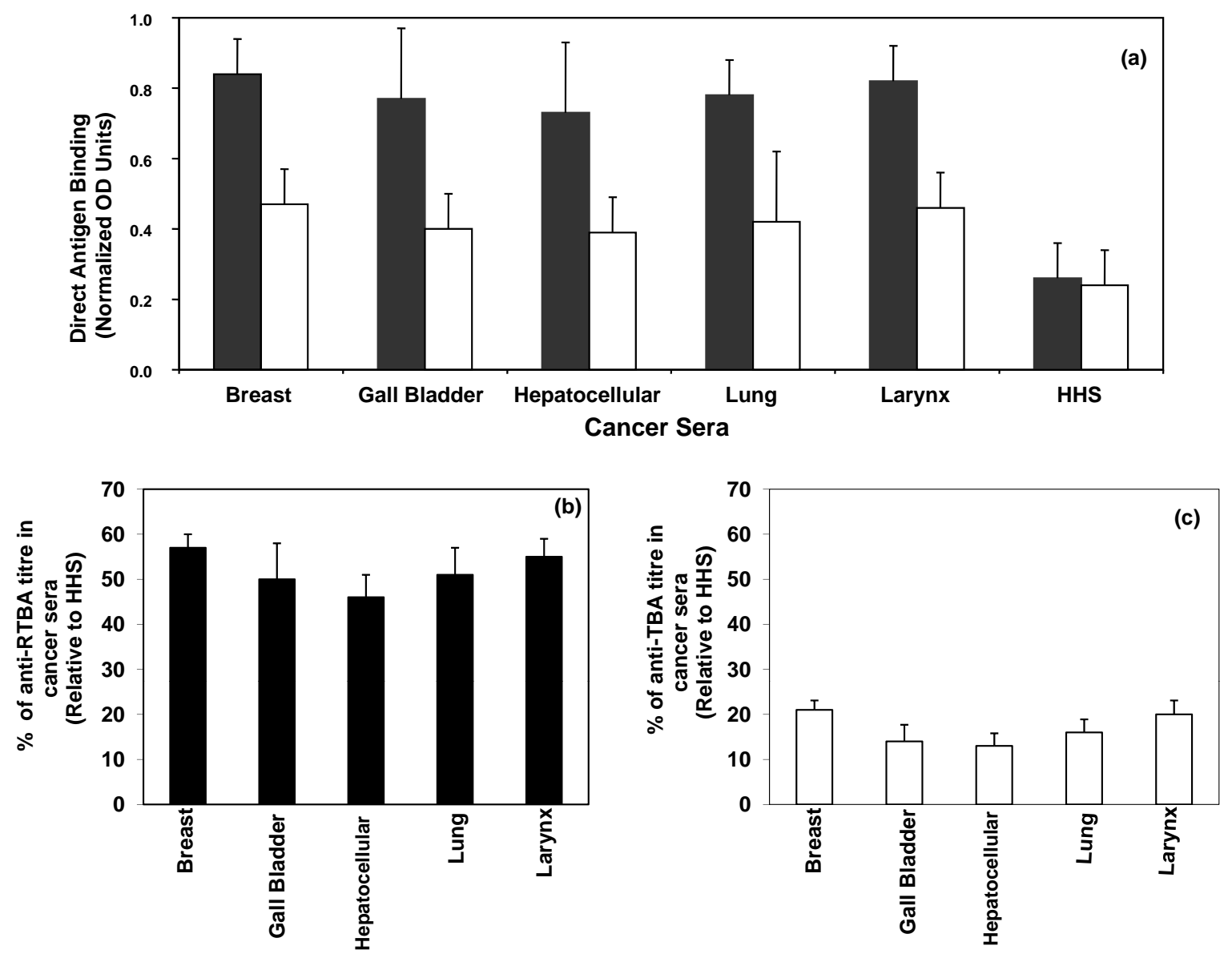

Fig. (2). (a) Direct binding ELISA of 1:100 diluted cancer serum samples to ROS-modified (a) and unmodified ( $\square$ ) TMP-BSA conjugate. The microtiter plates were coated with the respective antigens $(10 \mu \mathrm{g} / \mathrm{ml})$. (b) Percentage of anti-ROS-TMP-BSA antibodies (anti-RTBA) titre in cancer serum samples compared with healthy human sera (HHS). (c) Percentage of anti-TMP-BSA antibodies (anti-TBA) titre in cancer serum samples compared with HHS. Standard deviation has been indicated by a bar. The number of serum samples were 23 (breast), 21 (gall bladder), 22 (hapatocellular), 17 (lung), 16 (larynx) and 29 (HHS).

man sera binding to TMP-BSA and ROS-TMP-BSA conjugate antigens was $0.27 \pm 0.2$ and $0.26 \pm 0.1$, respectively. Percentage of cancer serum anti-ROS-TMP-BSA antibodies titre was found to be significantly high $(\mathrm{p}<0.001)$ in tested cancer serum samples, when compared with healthy human serum antibodies (Fig. 2b). Whereas, anti-TMP-BSA antibodies titre was significantly low (p>0.05) (Fig. 2c) as determined by direct binding ELISA. The binding specificity of antibodies from the sera of cancer patients was evaluated by competition ELISA using TMP-BSA and ROS-modified TMP-BSA conjugate as inhibitors. Microtitre plates were coated with ROS-modified TMP-BSA conjugate. The average maximum percent inhibition $( \pm \mathrm{SD})$ in the binding of 99 cancer sera to TMP-BSA and ROS-modified TMP-BSA conjugate was $29.3 \pm 6.5$ and $53.2 \pm 11.8$, respectively. The data reveals striking differences in the recognition of TMP-BSA conjugate and ROS-modified TMP-BSA conjugate by cancer antibodies $(p<0.05)$. Table 2 summaries direct binding and competition ELISA results of each studied cancer population sera. Results points to a strong reactivity of cancer sera towards modified TMP-BSA conjugate over unmodified TMPBSA conjugate.
IgGs were isolated from most of the cancer sera and also from healthy human sera using Protein-A sepharose CL-4B affinity column. The purified $\mathrm{IgG}$ was found to elute as a single symmetrical peak and gave a single band on SDSPAGE (data not shown). Affinity purified cancer anti-ROSTMP-BSA or anti-TMP-BSA IgGs titres were calculated and compared with the titre of IgG from healthy human subjects. Majority of cancer IgG showed high titre to ROS-TMP-BSA conjugate $(p<0.001)$ (Fig. 3a), whereas same purified cancer IgG showed low titre with TMP-BSA conjugate $(p>0.05)$ (Fig. 3b). The binding specificity of IgGs was investigated by inhibition ELISA using TMP-BSA and ROS-TMP-BSA conjugates as inhibitors. The microtitre plates were coated with ROS-TMP-BSA conjugate. Fig. (3 (c) and (d)) illustrate inhibition of affinity purified cancer IgGs (three IgGs from breast and three IgGs from gall bladder cancer) binding to ROS-TMP-BSA and TMP-BSA conjugates. Results point to a higher reactivity of cancer IgGs towards ROS-damaged TMP-BSA conjugate over TMP-BSA conjugate $(p<0.001)$ at $20 \mu \mathrm{g} / \mathrm{ml}$ of their respective inhibitor concentration. Similarly, the rest of the IgGs from other cancer population showed high percent inhibition with modified TMP-BSA 
Table 2. Immunological Details of Study Subjects

\begin{tabular}{|c|c|c|c|c|c|c|}
\hline \multirow[t]{3}{*}{ Type of Cancer Patients } & \multirow[t]{3}{*}{$\mathbf{N}^{\mathrm{a}}$} & \multirow[t]{3}{*}{$\begin{array}{c}\text { Age (Years) } \\
\text { Mean } \pm \text { SD }\end{array}$} & \multicolumn{2}{|c|}{$\begin{array}{c}\text { Detection of Anti-ROS-TMP-BSA } \\
\text { Antibodies }\end{array}$} & \multicolumn{2}{|c|}{ Detection of Anti-TMP-BSA Antibodies } \\
\hline & & & $\mathrm{A}_{410}$ & MPI & $\mathrm{A}_{410}$ & MPI \\
\hline & & & \multicolumn{2}{|c|}{ (ROS-TMP-BSA) } & \multicolumn{2}{|c|}{ (TMP-BSA) } \\
\hline Breast & 23 & $45.2 \pm 7.2$ & $0.84^{\mathrm{b}} \pm 0.1$ & $59.7^{\mathrm{c}} \pm 13.1$ & $0.47 \pm 0.1$ & $29.3 \pm 6.1$ \\
\hline Gall bladder & 21 & $51.4 \pm 6.4$ & $0.77^{\mathrm{b}} \pm 0.2$ & $56.9^{\mathrm{c}} \pm 15.7$ & $0.40 \pm 0.1$ & $30.6 \pm 7.9$ \\
\hline Hepatocellular & 22 & $58.3 \pm 6.4$ & $0.73^{\mathrm{b}} \pm 0.2$ & $43.8^{\mathrm{c}} \pm 6.8$ & $0.39 \pm 0.1$ & $27.8 \pm 5.9$ \\
\hline Lung & 17 & $64.3 \pm 4.1$ & $0.78^{\mathrm{b}} \pm 0.1$ & $51.0^{c} \pm 10.9$ & $0.42 \pm 0.2$ & $29.0 \pm 6.2$ \\
\hline Larynx & 16 & $44.5 \pm 10.6$ & $0.82^{\mathrm{b}} \pm 0.1$ & $54.6^{\mathrm{c}} \pm 12.7$ & $0.46 \pm 0.1$ & $30.0 \pm 6.5$ \\
\hline HHS & 29 & $55.8 \pm 9.4$ & $0.27 \pm 0.2$ & $17.7^{\mathrm{c}} \pm 1.4$ & $0.26 \pm 0.1$ & $16.3 \pm 4.8$ \\
\hline
\end{tabular}

$\mathrm{N}^{\mathrm{a}}$ : Number of cancer tested sera; HHS: healthy human sera; $\mathrm{A}_{410}$ : absorbance at $410 \mathrm{~nm}$ calculated by direct binding ELISA; MPI: maximum percent inhibition at $20 \mu \mathrm{g} / \mathrm{ml}$ of inhibitor concentration calculated by competitive inhibition ELISA. ${ }^{\mathrm{b}} p<0.05 \mathrm{vs}$. $\mathrm{A}_{410}$ (TMP-BSA); ${ }^{\mathrm{c}} p<0.01 \mathrm{vs}$. MPI(TMP-BSA).
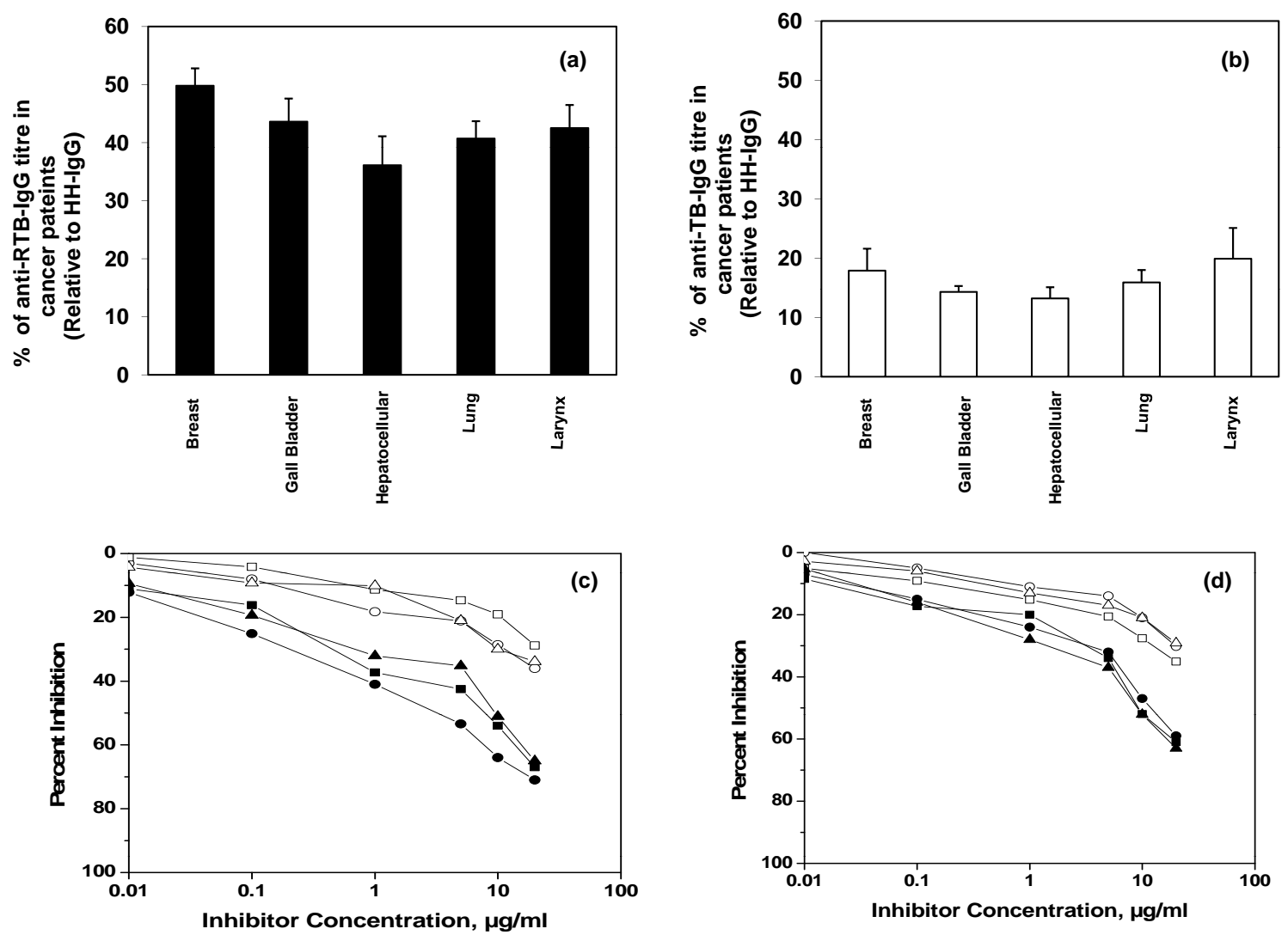

Fig. (3). (a) Percentage of affinity purified cancer anti-ROS-TMP-BSA IgG (anti-RTB-IgG) titre compared with healthy human sera IgG (HH-IgG). (b) Percentage of affinity purified cancer anti-TMP-BSA IgG (anti-TB-IgG) titre compared with HH-IgG. Standard deviation has been indicated by a bar. The number of IgGs samples were 23 (breast), 21 (gall bladder), 22 (hapatocellular), 17 (lung), 16 (larynx) and 29 (healthy human). Inhibition ELISA of affinity purified IgG from breast (c) and gall bladder (d) cancer patients. The inhibitors used were TMP-BSA $(\square, \Delta, \circ)$ and ROS-TMP-BSA conjugate $(\boldsymbol{\bullet}, \boldsymbol{\Lambda}, \bullet)$. The microtiter plates were coated with ROS-TMP-BSA conjugate $(10 \mu \mathrm{g} / \mathrm{ml})$.

conjugate over unmodified TMP-BSA conjugate (data are summarized in Table $\mathbf{3}$ ).

\section{DISCUSSION}

Malignant diseases are associated with the induction of autoimmunity that is characterized by the generation of autoantibodies against a wide array of autoantigens. Autoantibody activity has been identified in the sera of patients with solid tumors and in the sera of patients with hematological malignancies. The anti-tumor immune response may result in elicitation of autoantibodies against various autoantigens, including self antigens expressed in tumor cells - a large 
Table 3. Inhibition Data of Affinity Purified Cancer IgG with ROS-modified TMP-BSA and TMP-BSA Conjugates

\begin{tabular}{|c|c|c|c|}
\hline \multirow{2}{*}{ Type of Cancer IgG } & \multirow{2}{*}{$\mathbf{N}^{\mathrm{a}}$} & \multicolumn{2}{|c|}{ Maximum Percent Inhibition at 20 $\mu \mathrm{g} / \mathrm{ml}$} \\
\cline { 3 - 4 } & & ROS-TMP-BSA Conjugate & $34.1 \pm 4.4$ \\
\hline \hline Breast & 15 & $67.4 \pm 3.7^{\mathrm{b}}$ & $30.5 \pm 1.6$ \\
\hline Gall bladder & 13 & $61.2 \pm 2.2^{\mathrm{b}}$ & $29.4 \pm 3.4$ \\
\hline Hepatocellular & 11 & $53.7 \pm 3.7^{\mathrm{b}}$ & $32.1 \pm 2.5$ \\
\hline Lung & 10 & $58.3 \pm 4.1^{\mathrm{b}}$ & $36.1 \pm 5.6$ \\
\hline Larynx & 11 & $60.1 \pm 3.2^{\mathrm{b}}$ & $16.2 \pm 2.4$ \\
\hline
\end{tabular}

$\mathrm{N}^{\mathrm{a}}$ : Number of cancer IgG tested; ${ }^{\mathrm{b}} p<0.001$ vs. TMP-BSA. The microtitre plates were coated with ROS-TMP-BSA conjugate $(10 \mu \mathrm{g} / \mathrm{ml})$.

group of autoantigens designated as tumor associated autoantigens $[2,3,12,19]$.

Reactive oxygen species (ROS) generated during numerous metabolic and biochemical reactions have multifarious effects that include oxidative damage to DNA leading to various human degenerative diseases $[2,3,12,20]$. Cancer and aging are two biological consequences with the most complex etiology, and free radical-induced damage to DNA has been postulated to play a major role in their pathogenesis [10]. Native DNA is known to be a poor immunogen [21], whereas RNA-DNA hybrid, synthetic ribohomopolymers of poly $(\mathrm{I})$, poly $(\mathrm{U})$, poly $(\mathrm{G})$ and calf-thymus DNA modified with drug, free radical, etc., have been reported to induce antibodies [22-24]. Despite of enzymatic repair and other defenses, continuous ROS damage and division of cells with unrepaired or misrepaired lesions lead to mutations. If these relate to critical genes such as oncogenes or tumor suppressor genes, initiation and/or progression of cancer can occur. Of the DNA bases thymine and guanosine are highly susceptible to hydroxyl radical modification to form products such as thymine glycol (Tg) and 5-hydroxymethyluracil (5-HMU) and 8-hydroxydeoxyguanosine (8-HDG). The Tg and 5HMU have been detected in human urine in addition to 8HDG thereby indicating their in vivo formation as a consequence of hydroxyl radical damage to DNA [25]. Studies have shown that 8 -HDG is the major mutagenic lesion associated with increased risk of cancer. In our previous report, TMP and TMP-BSA were modified by hydroxyl radical, generated by UV-irradiation of hydrogen peroxide at 254 $\mathrm{nm}$. Hydroxyl radicals caused extensive damage on TMP as evident by UV spectral studies. The observed hypochromicity was due to the structural alteration in TMP [13]. The antigens TMP-BSA, and ROS-TMP-BSA conjugates induced highly specific antibodies against their respective immunogens. Induced antibodies exhibited appreciable crossreactivity with various polynucleotides and nucleic acid [13]. It is well documented that experimentally-induced antibodies to purines/pyrimidines conjugated to BSA are quite specific, but do cross-react with nucleic acids from various sources [26]. The diverse antigen-binding characteristics of the induced antibodies with a variety of polynucleotides and their ROS-modified forms might be due to the recognition of either the phosphodiester backbone or neo-epitopes on the molecules but the chances of neo-epitopes recognition by induced antibodies appears to be dominating in view of the practical negligible recognition of unmodified nucleic acids and their derivatives by induced antibodies $[13,26]$. In the present study, we demonstrated the cross reactivity of induced anti-TMP-BSA antibodies and anti-ROS-TMP-BSA antibodies to TMP and BSA alone and their ROS- modified conformers to find out which is the actual antigen for these antibodies. The anti-TMP-BSA antibodies and anti-ROSTMP-BSA antibodies showed negligible inhibition with native and ROS-modified BSA alone, but these antibodies showed significant inhibition with both TMP alone and its ROS-modified form. This indicates that the induced antiTMP-BSA antibodies and anti-ROS-TMP-BSA antibodies are mainly generated against TMP and ROS-TMP respectively, not against native BSA or ROS-modified BSA.

We know increased levels of circulating antibodies and autoantibodies have been reported in the serum of patients with malignancies directed against nucleus [25] and elevated levels of anti-nuclear antibodies (ANA) have been reported in the serum of cancer patients [27,28]. In view of these, present study was designed to evaluate the binding of circulating antibodies in cancer patients with TMP and ROSmodified TMP. In our study, sera from different types of cancer patients were screened for the presence of antibodies reactive to TMP-BSA and ROS-TMP-BSA conjugates. The study consists of 99 sera from patients of breast, gall bladder, hepatocellular, lung and larynx carcinomas having differences in the stage or other diagnostic parameters within each cancer type but all cancer patients were proven histopathological diagnosis and all cancer patients having disease for more than eighteen months and they continuing attending their O.P.D. at J.N. Medical College Hospital, A.M.U. Aligarh and All India Institute of Medical Sciences, New Delhi. Severity of cancer vary from patient to patients. The Majority of patients sera showed significantly higher recognition of ROS-modified TMP-BSA conjugate as compared to native TMP-BSA conjugate $(\mathrm{p}<0.05)$, whereas the antibodies present in the healthy human sera showed negligible binding to either of the conjugates ( $p>0.05)$. The binding of TMPBSA and ROS-TMP-BSA conjugates with circulating cancer antibodies was further substantiated by Protein-A affinity purified cancer IgG by competition ELISA. Studies on the binding specificity of cancer antibodies clearly demonstrate that ROS-modified TMP-BSA conjugate is a better inhibitor 
of naturally occurring antibodies in most of the cancer sera (or cancer IgG) investigated. The present study clearly shows the perturbations in TMP-BSA conjugate by hydroxyl radical presenting unique neo-epitopes on TMP that might form one of the factors in antigen-driven induction of antibodies in cancer patients.

The link between autoimmunity and cancer may result from a common aetiological origin (genetic, hormonal, or environmental factors) or, alternatively, from paraneoplastic syndromes. A large number of autoantibodies have been identified [2,3], these autoantibodies represent potentially valuable tools for identifying novel biomarkers and therapeutic targets. Recently, it has been proved that the inherent amplification of signals provided by the host's own immune system to low levels of tumor-associated antigens in early disease provides a potential route to the early diagnosis of cancer $[28,29]$. Further studies are required to assess the diagnostic and/or prognostic value of autoantibodies reacting with polynucleotides, modified DNA, DNA-protein adducts, oncoproteins, tumor suppression genes, and/or proliferation associated antigens. The great studies in autoantibody testing over the last 20 years make it feasible to use specific autoantibody markers to improve diagnostic accuracy in systemic autoimmune disease. Circulating autoantibodies to selfantigens over expressed by cancer cells are common in cancer patients.

Our results demonstrate the presence of ROS-induced TMP damage in cancer patients, which might play an active part in the progression of disease mediated by mutations and subsequent neoplastic transformation of cells. Earlier studies report the use of antibodies to specific DNA base alterations, DNA-carcinogen adducts or to UV-DNA [30,31]. Some of these did not detect their target epitopes in macromolecular DNA. In contrast, the anti-ROS-TMP antibodies have been clearly shown to represent an alternative immunochemical probe to detect oxidative lesions in DNA from cancer patients, which could perhaps have a prognostic significance. These novel detection of oxidative thymidine-5'-monophosphate in cancer patients provide suggestions that the use of antioxidant or compounds that contain antioxidant may help human health.

\section{COMPETING INTERESTS} ests.

The authors declare that they have no competing inter-

\section{AUTHORS' CONTRIBUTIONS}

R. Ahmad carried out the experimental work. Z. Rasheed conceived of the study, coordination, data interpretation and drafting the manuscript. Study was designed by R. Ali.

\section{ACKNOWLEDGEMENTS}

The authors would like to thank Prof. Ashok Kumar for providing most of the cancer serum samples. Supported by a research grant from ICMR is gratefully acknowledged.

\section{REFERENCES}

[1] Tubiana M. Generalities about carcinogenesis. C R Biol 2008; 331: $114-25$.

[2] Rasheed Z, Ahmad R, Ali R. Structure and immunological function of oxidized albumin in lung cancer: its potential role as a biomarker of elevated oxidative stress. Br J Biomed Sci 2009; 66: 67-73.
[3] Rasheed Z, Ahmad R, Rasheed N, Ali R. Reactive oxygen species damaged human serum albumin in patients with hepatocellular carcinoma. J Exp Clin Cancer Res 2007; 26: 515-24.

[4] Slemmer JE, Shacka JJ, Sweeney MI, Weber JT. Antioxidants and free radical scavengers for the treatment of stroke, traumatic brain injury and aging. Curr Med Chem 2008; 15: 404-14.

[5] Haleng J, Pincemail J, Defraigne JO, Charlier C, Chapelle JP. Oxidative stress. Rev Med Liege 2007: 62: 628-38.

[6] Sandercock LE, Hahn JN, Li L, et al. Mgmt deficiency alters the in vivo mutational spectrum of tissues exposed to the tobacco carcinogen 4-(methylnitrosamino)-1-(3-pyridyl)-1-butanone (NNK). Carcinogenesis 2008; 29: 866-74.

[7] Breen AP, Murphy JA. Reaction of oxy-radicals with DNA. Free Rad Biol Med 1995; 18: 1033-77.

[8] Loft S, Poulsen HE. Cancer risk and oxidative DNA damage in man. J Mol Med 1996; 74: 297-312.

[9] Dizdaroglu M. Chemical determination of oxidative DNA damage by gas chromatography-mass spectrometry. Methods Enzymol 1994; 234: 3-16.

[10] Ames BN, Shigenaga MK, Gold S. DNA lesions, inducible DNA repair, and cell division: three key factors in mutagenesis and carcinogenesis. Environ Health Perspect 1990; 101: 35-44.

[11] Lau AT, Wang Y, Chiu JF. Reactive oxygen species: current knowledge and applications in cancer research and therapeutic. $\mathrm{J}$ Cell Biochem 2008; 104: 657-67.

[12] Ashok BT, Ali R. Binding of human anti-DNA autoantibodies to reactive oxygen species modified DNA and probing oxidative DNA damage in cancer using monoclonal antibody. Int J Cancer 1998; 78: 404-9.

[13] Ahmad R, Alam K, Ali R. Antigen binding characteristics of antibodies against hydroxyl radical modified thymidine monophosphate. Immunol Lett 2000; 71: 111-50.

[14] Halloran MJ, Parker CW. The preparation of nucleotide-protein conjugates: carbodiimide as coupling agent. J Immunol 1996; 96: 373-8.

[15] Rasheed Z, Ali R. Reactive oxygen species damaged human serum albumin in patients with type 1 diabetes mellitus: biochemical and immunological studies. Life Sci 2006; 79: 2320-8.

[16] Rasheed Z, Khan MWA, Ali R. Hydroxyl radical modification of human serum albumin generated cross reactive antibodies. Autoimmunity 2006; 39: 479-8.

[17] Rasheed Z, Ahmad R, Rasheed N, Ali R. Enhanced recognition of reactive oxygen species damaged human serum albumin by circulating systemic lupus erythematosus autoantibodies. Autoimmunity 2007; 40: 512-20.

[18] Rasheed Z. Hydroxyl radical damaged immunoglobulin G in patients with rheumatoid arthritis: biochemical and immunological studies. Clin Biochem 2008; 41: 633-9.

[19] Garcia-Hernandez ML, Gray A, Hubby B, Klinger OJ, Kast WM. Prostate stem cell antigen vaccination induces a long-term protective immune response against prostate cancer in the absence of autoimmunity. Cancer Res 2008; 68: 861-9.

[20] Madrid F, Karvonen RL, Ensley J, et al. Spectra of antinuclear antibodies in patients with squamous cell carcinoma of the lung and of the head and neck. Cancer Detect Prev 2005; 29: 59-65.

[21] Madaio MP, Hodder S, Schwartz RS, Stollar BD. Responsiveness of autoimmune and normal mice to nucleic acid antigens. J Immunol 1984; 132: 872-6.

[22] Alam K, Ali A, Ali R. The effect of hydroxyl radical on the antigenicity of native DNA. FEBS Lett 1993; 319: 66-70.

[23] Garg DK, Ali R. Reactive oxygen species modified polyguanylic acid: immunogenicity and implications for systemic autoimmunity. J Autoimmun 1998; 11:371-8.

[24] Arif Z, Ali R. Antigenicity of poly(dA-dT). poly(dA-dT) photo cross linked with 8-methoxypsoralen. Arch Biochem Biophys 1996; 329: 191-8.

[25] Imai H, Nakano Y, Kiyosawa K, Tan EM. Increasing titers and changing specificities of antinuclear antibodies in patients with chronic liver disease who develop hepatocellular carcinoma. Cancer 1993; 71: 26-35.

[26] Ballard DW, Voss EW Jr. Base specificity and idiotypy of antiDNA autoantibodies reactive with synthetic nucleic acids. J Immunol 1985; 135: 3372-80.

[27] Imai H, Ochs RL, Kiyosawa K, Furuta S, Nakamura RM, Tan EM. Nucleolar antigens autoantibodies in hepatocellular carcinoma and other malignancies. Am J Pathol 1992; 140: 859-70. 
[28] Feist E, Brychcy M, Hausdorf G, et al. Anti-proteasome autoantibodies contribute to anti-nuclear antibody patterns on human larynx carcinoma cells. Ann Rheum Dis 2007; 66: 5-11.

[29] Storr SJ, Chakrabarti J, Barnes A, Murray A, Chapman CJ, Robertson JFR. Use of autoantibodies in breast cancer screening and diagnosis. Expert Rev Anticancer Ther 2006; 6: 1215-23.
[30] Herbert KE, Mistry N, Griffiths HR, Lunec J. Immunochemical detection of sequence-specific modifications to DNA induced by UV light. Carcinogenesis 1994; 15: 2517-21.

[31] Yin B, Whyatt RM, Perera FP, Randall MC, Cooper TB, Santella RM. Determination of 8-hydroxydeoxyguanosine by an immunoaffinity chromatography-monoclonal antibody based ELISA. Free Radic Biol Med 1995; 18: 1023-32.

(C) Ahmad et al.; Licensee Bentham Open.

This is an open access article licensed under the terms of the Creative Commons Attribution Non-Commercial License (http://creativecommons.org/licenses/by-nc/3.0/) which permits unrestricted, non-commercial use, distribution and reproduction in any medium, provided the work is properly cited. 